\title{
Rancang Bangun Sistem Informasi Penjualan Online (E-Commerce) Pada Toko Batik Pekalongan Dengan Metode Waterfall
}

\author{
Nia Nuraeni ${ }^{1}$, Puji Astuti ${ }^{2}$ \\ ${ }^{1}$ STMIK Nusa Mandiri Jakarta \\ e-mail: nia.nne@nusamandiri.ac.id \\ ${ }^{2}$ STMIK Nusa Mandiri Jakarta \\ e-mail: puji.past@nusamandiri.ac.id
}

\begin{abstract}
Pekalongan Batik is a typical batik originating from Central Java Pekalongan, Pekalongan batik has been well known in various regions in Indonesia. Nowadays batik is an Indonesian culture so every company or government institution requires using batik on one day during their working hours. Pekalongan batik producers in Central Java, of course, have difficulty in marketing their products, especially marketing outside Central Java. E-Commerce is one of the solutions to these problems. Internet networks that are not limited to space and time can of course make it easier for manufacturers to market their products. E-Commerce is the best solution, as a marketing and promotional media for Pekalongan batik by anyone, anywhere and anytime. Use of PHP programming language, SQL database and adobe Dreamweaver application is used to design this online sales website with the SDLC (Systems Development Life Cycle) method in applying the website creation method.
\end{abstract}

Keywords: Batik Pekalongan, E-Commerce, SDLC (Systems Development Life Cycle), Website

\section{PENDAHULUAN}

Batik pekalongan merupakan pakaian tradisional yang sudah terkenal di wilayah indonesia, selain itu batik pekalongan juga sudah di ekspor ke negaranegara luar. Namun dalam proses pemasarannya masih banyak pengrajin atau penjual menggunakan cara-cara yang kalsik dan sederhana, tentu saja ini tidak menjadi masalah karna sampai sekarang ini pun proses pemasaran tersebut masih terlaksana dengan baik, akan tetapi pada prosesnya masih banyak kendala yang terjadi terutama untuk pemasarandan pendistribusian batik pekalongan dalam jumlah besar.

R3N Batik Pekalongan yang saat ini berlokasi di Pekalongan Jawa Tengah memiliki kendala pada saat pendistributian batik nya terutama jika pendistribusian batik nya dalam jumlah besar karna R3N Batik masih menggunakan metode penjualan dengan cara memasarkan secara tradisional yaitu dengan cara melakukan pendistribusian produk kepada konsumen secara langsung. Penjualan secara online atau e-commerce menjadi salah satu alternative permasalahan mengingat banyaknya jumlah pengguna internet di Indonesia. Jumlah pengguna internet aktif di Indonesia yang mencapai 73 juta pengguna dimana 7\%-nya melakukan transaksi jual-beli melalui internet. Hal ini mendorong terciptanya e-commerce yang makin diminati oleh masyarakat Indonesia.

E-commerce merupakan proses membeli dan menjual produk secara elektronik oleh konsumen dan dari perusahaan ke perusahaan dengan komputer dan internet sebagai perantara transaksi bisnis. Pada tahun 2014, nilai transaksi e-commerce mencapai $\$ 12$ Miliar atau $\mathrm{Rp} 150$ Triliun. Pemerintah menetapkan target untuk transaksi sampai dengan tahun 2016 mencapai \$24 Miliar atau Rp 300 Triliun (www.kominfo.go.id ). Data tersebut menjadi potensi tersendiri untuk peningkatan jumlah konsumen bagi R3N Batik Pekalongan.

Diharapkan dengan adanya website e-commerce yang memanfaatkan internet sebagai media pemasaran dapat memudahkan pemilik R3N Batik untuk memberikan pelayanan terhadap kosumen secara optimal dan memberikan informasi 24 jam serta dapat diakses kapan saja dan dimana saja (Himawan, Saefullah, \& Santoso, 2018). 


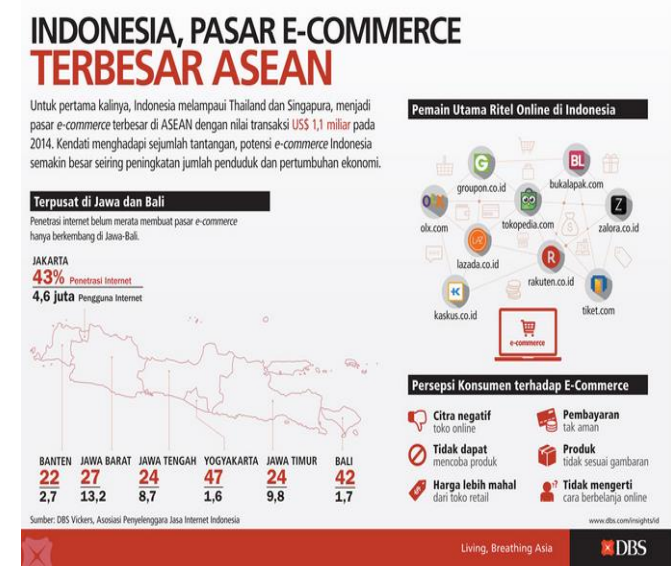

sumber: (www.kominfo.go.id )

Gambar 1 Perkembangan Pasar E-commerce di Indonesia

\section{a. Penjualan Online (E-Commerce)}

Perdagangan elektronik yang disebut juga ecommerce adalah penggunaan jaringan komunikasi dan komputer untuk melaksanakan proses bisnis (Sadeli, 2013). E-commerce merupakan penyebaran, penjualan, pembelian, pemasaran barang dan jasa yang dilakukan oleh seorang konsumen melalui system elektronik seperti internet.

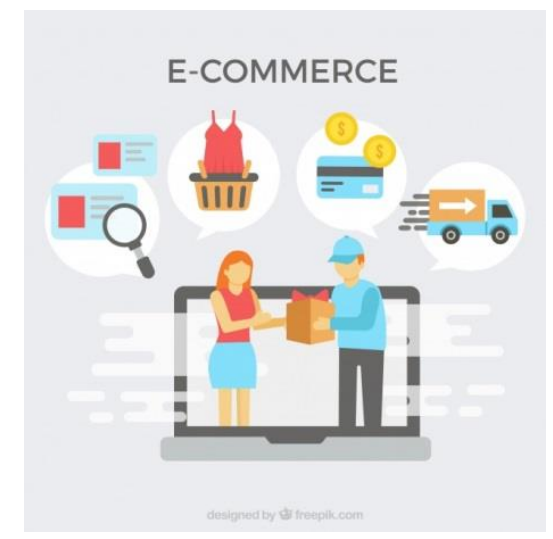

Sumber: (www.kominfo.go.id )

Gambar 2 Contoh Ilustrasi e-commerce

\section{b. Website}

Website diartikan sebagai salah satu aplikasi dengan beragam dokumen multimedia (teks, gambar, animasi, video) didalamnya yang menggunakan protocol HTTP (Hypertext Transfer Protocol) dan untuk mengaksesnya menggunakan perangkat lunak yang disebut browser (Arief, 2011)

c. UML (Unified Modeling Language)

UML (Unified Modeling Language) adalah "Bahasa" pemodelan untuk sistem atau perangkat lunak yang berparadigma "Berorientasi objek". Pemodelan sesungguhnya digunakan untuk penyederhanaan permasalahan- permasalahan yang kompleks sedemikian rupa sehingga lebih mudah dipelajari dan dipahami. (Nugroho, 2010) Berikut adalah klasifikasi diagram yang ada pada UML:

1) Use Case Diagram

Use case adalah abstraksi dari interaksi antara sistem dan aktor. Use case diagram bekerja dengan cara mendeskripsikan tipe interaksi antara user sebuah sistem dengan sistemnya sendiri melalui sebuah cerita bagaimana sebuah sistem dipakai

2) Class Diagram

Class diagram UML digambarkan dengan kotak, class adalah spesifikasi yang jika diinstansiasi akan menghasilakn sebuah objek dan merupakn inti dari pengembangan dan desain berorientasi objek. Class menggambarkan keadaan (atribut/propeti) suatu system, sekaligus menawarkan layanan untuk memanipulasi keadaan tersebut (metode/fungsi).

3) Statechart Diagram

Statechart diagram atau yang biasa juga disebut state diagram digunakan untuk mendokumentasikan beragaam kondisi/keadaan yang bisa terjadi terhadap sebuah class dan kegiatan apa saja yang dapat merubah kondisi/keadaan tersebut. Pada umunya statechart diagram menggambarkan class tertentu (satu class dapat memliki lebih dari satu statechart diagram)

\section{METODOLOGI PENELITIAN}

a. Teknik Pengumpulan Data

Metode pengumpulan data yang penulis lakukan dalam penelitian ini adalah

\section{Observasi}

Observasi adalah mengamati langsung terhadap kegiatan yang sedang terjadi, untuk mendapatkan data-data yang lengkap dan akurat. Pada metode observasi ini penulis melakukan pengamatan dengan cara mengamati setiap toko serupa yang memiliki permasalahan yang sama.

\section{Studi Pustaka}

Metode ini membantu penulis dalam hal membuat laporan yang ditunjang dengan buku-buku, jurnal, internet dan referensi yang berhubungan dengan masalah yang dimuat.

b. Metode Pengembangan Perangkat Lunak

Metodologi pengembangan sistem artinya menyusun sistem yang baru untuk menggantikan sistem lama dikarnakan sistem lama perlu di perbaiki karna adanya permasalahan-permasalahan yang timbul. Siklus hidup pengembangan system (System Development Life Cycle) atau SDLC adalah model SDLC yang paling sederhana, model ini hanya cocok untuk pengembangan perangkat lunak 
dengan spesifikasi yang tidak berubah-ubah. (R. A. M. . Sukamto, 2013)

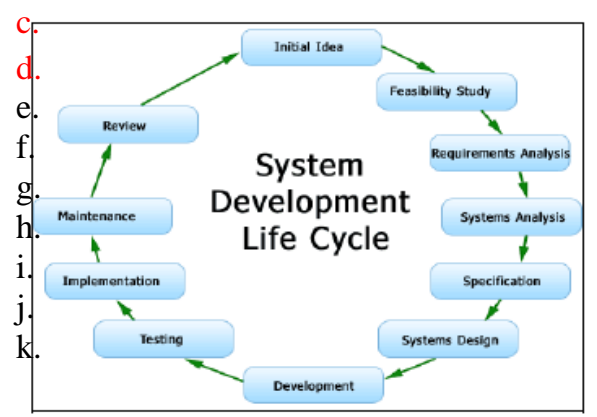

Gambar 3 Pengembangan Sistem SDLC

Model Waterfall (SDLC) menyediakan pendekatan alur hidup perangkat lunak secara sekuensial atau terurut dimulai dari analisis, desain, pengodean, pengujian dan tahap pendukung (support) (R. . Sukamto \& Shalahudin, 2014).

1. Analisis kebutuhan perangkat lunak Proses pengumpulan kebutuhan dilakukan secara intensif untuk menspesifikasikan kebutuhan perangkat lunak agar dapat dipahami perangkat lunak seperti apa yang dibutuhkan oleh user. Spesifikasi kebutuhan perangkat lunak pada tahap ini perlu didokumentasikan.

2. Desain

Desain perangkat lunak proses multi langkah yang fokus pada desain pembuatan program perangkat lunak termasuk struktur data, arsitektur perangkat lunak, representasi antar muka dan prosedur pengkodean. Tahap ini mentranslasi kebutuhan perangkat lunak dari tahap analisis kebutuhan ke representasi desain agar dapat diimplementasikan menjadi program pada tahap selanjutnya. Desain perangkat lunak yang dihasilkan pada tahap ini juga perlu didokumentasikan.

3. Pembuatan kode program

Desain harus ditranslasikan ke dalam program perangkat lunak. Hasil dari tahap ini adalah program komputer sesuai dengan desain yang telah dibuat pada tahap desain.

4. Pengujian

Pengujian fokus pada perangkat lunak secara dari segi lojik dan fungsional dan memastikan bahwa semua bagian sudah diuji. Hal ini dilakukan untuk meminimalisir kesalahan (error) dan memastikan keluaran yang dihasilkan sesuai yang diinginkan.

5. Pendukung (support) atau pemeliharaan (maintenance)

Tidak menutup kemungkinan sebuah perangkat lunak mengalami perubahan ketika sudah dikirimkan ke user. Perubahan bisa terjadi karena adanya kesalahan yang muncul dan tidak terdeteksi saat pengujian atau perangkat lunak harus beradaptasi dengan lingkungan baru. Tahap pendukung atau pemeliharaan dapat mengulangi proses pengembangan mulai dari analis spesifikasi untuk perubahan perangkat lunak yang sudah ada, tapi tidak untuk membuat perangkat lunak baru. Tahap ini bisa dikatakan final dalam pembuatan suatu aplikasi atau sistem. Setelah melakukan analisis, desain maka sistem ini akan digunakan oleh pengguna. Kemudian aplikasi yang telah dibuat harus dilakukan pemeliharaan

\section{HASIL DAN PEMBAHASAN}

\section{Prosedur Sistem yang diusulkan}

a. Pengolahan Data Pelanggan

Proses pengolahan data pelanggan, dilakukan oleh sedorang administrator, dimana saat seorang pengunjung ingin berbelanja, maka pengunjung tersebut harus menjadi seorang pelanggan dengan cara login terlebih dahulu ke website. Untuk melakukan login pelanggan harus mengisi form pendaftaran yang telah disediakan kemudian mengirim data tersebut, sehingga admin akan mendapatkan konfirmasi data pelanggan baru.

b. Pengolahan pemesanan produk

Pelanggan yang telah melakukan login melakukan pemilihan produk, setelah memilih produk pelanggan tersbut memesan produk dan secara otomatis masuk ke keranjang belanja, admin akan mendaptak konfirmasi pemesanan produk baru, setelah itu admin mengecek stok produk setelah tersedia, admin mengirimkan faktur produk dan no rekening toko kepada pelanggan.

c. Pengolahan data pembayaran

Saat pelanggan memasukan produk ke keranjang belanja, plenggan melakukan checkout, setelah itu pelanggan menerima konfirmasi faktur dan nomor rekening toko, kemudian pelanggan melakukan transfer melalui Bank yang telah ditunjuk oleh toko, setelah melakukan transfer pelanggan melakukan konfirmasi pembayaran. Dan mendapatkan konfirmasi telah melakukan pembayaran melalui email.

\section{ERD (Entity Relational Diagram) dan LRS (Logical Relational Structure)}

ERD merupakan teknik yang digunakan untuk memodelkan kebutuhan data dari suatu organisasi, biasanya oleh sistem analis dalam tahap analisis persyaratan proyek pengembangan sistem. (Brady \& Loonam, 2010). LRS adalah representasi dari struktur record-record pada tabel-tabel yang 
terbentuk dari hasil relasi antar himpunan entitas. ( $\mathrm{R}$. . Sukamto \& Shalahudin, 2014).

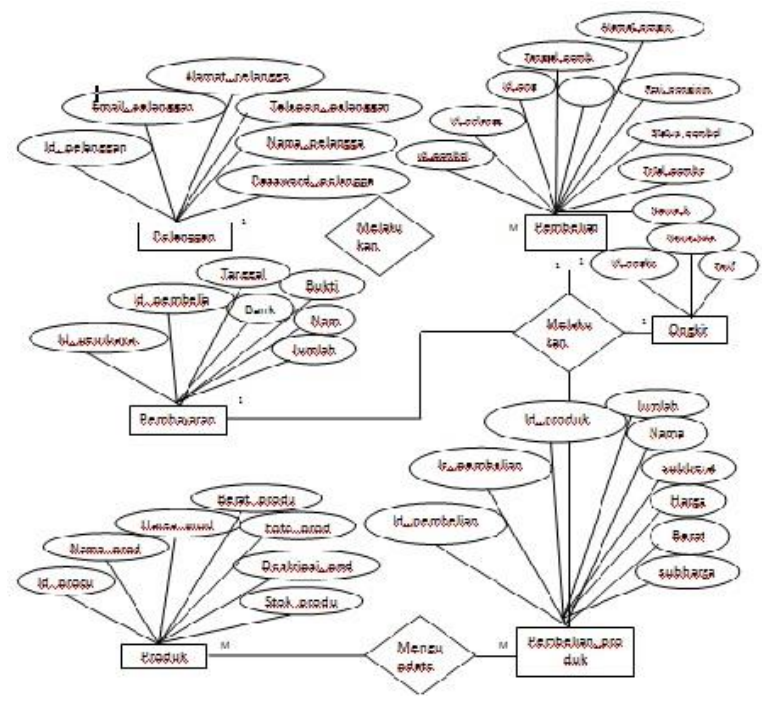

Gambar 4 ERD Penjualan Online

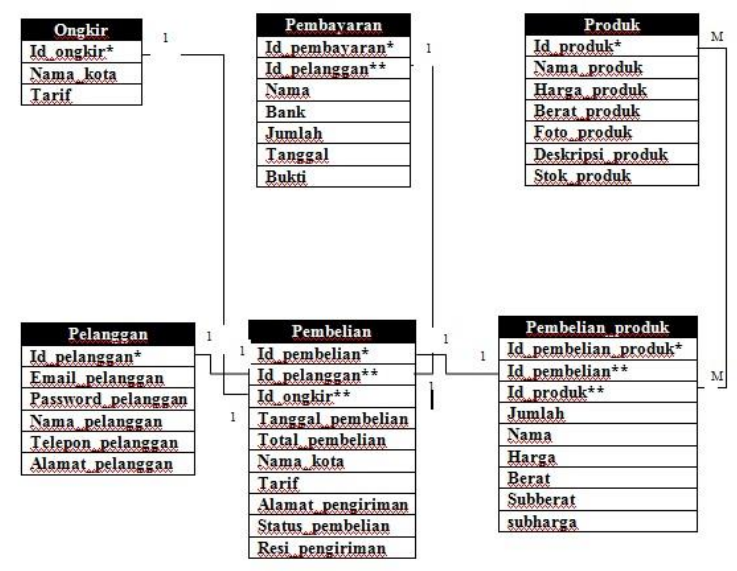

Gambar 5. LRS Penjualan Online

\section{Desain Sistem (UML)}

Unified Modeling Language (UML) adalah bahasa Spesifikasi standard untuk mendokumentasikan, menspesifikasikan dan membangun system perangkat lunak

a. Use Case

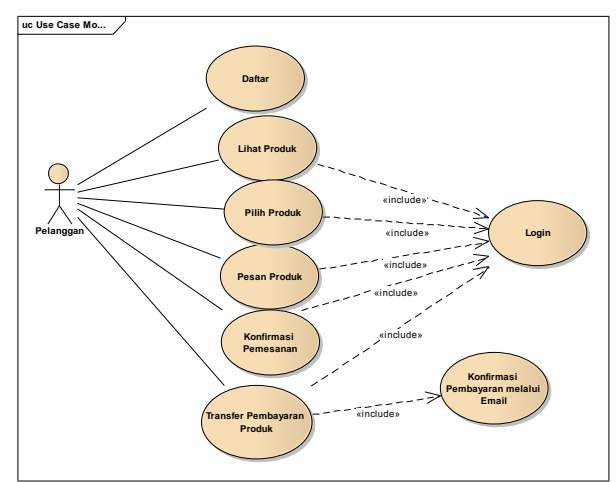

Gambar 6. Use Case Pelanggan Order Produk

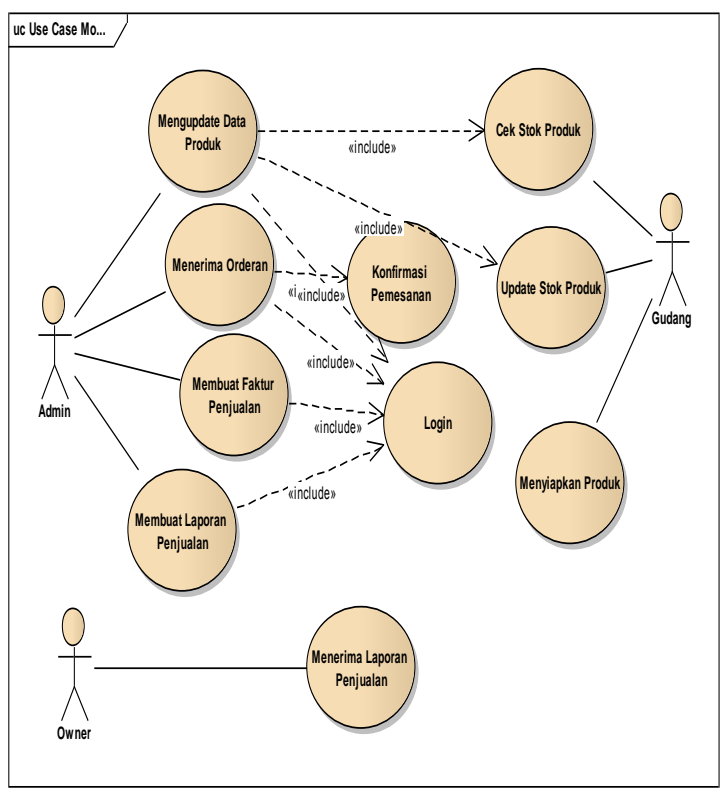

Gambar 7. Use Case Proses Penjualan Online (ECommerce)

b. Activity Diagram

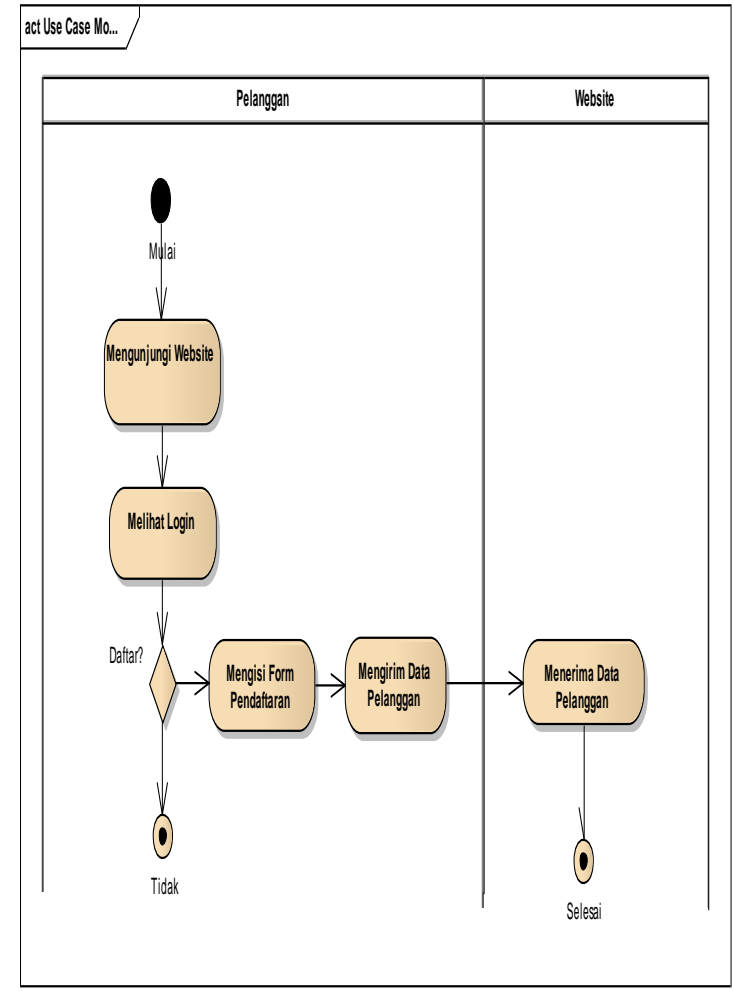

Gambar 8 Activity Diagram Pelanggan 


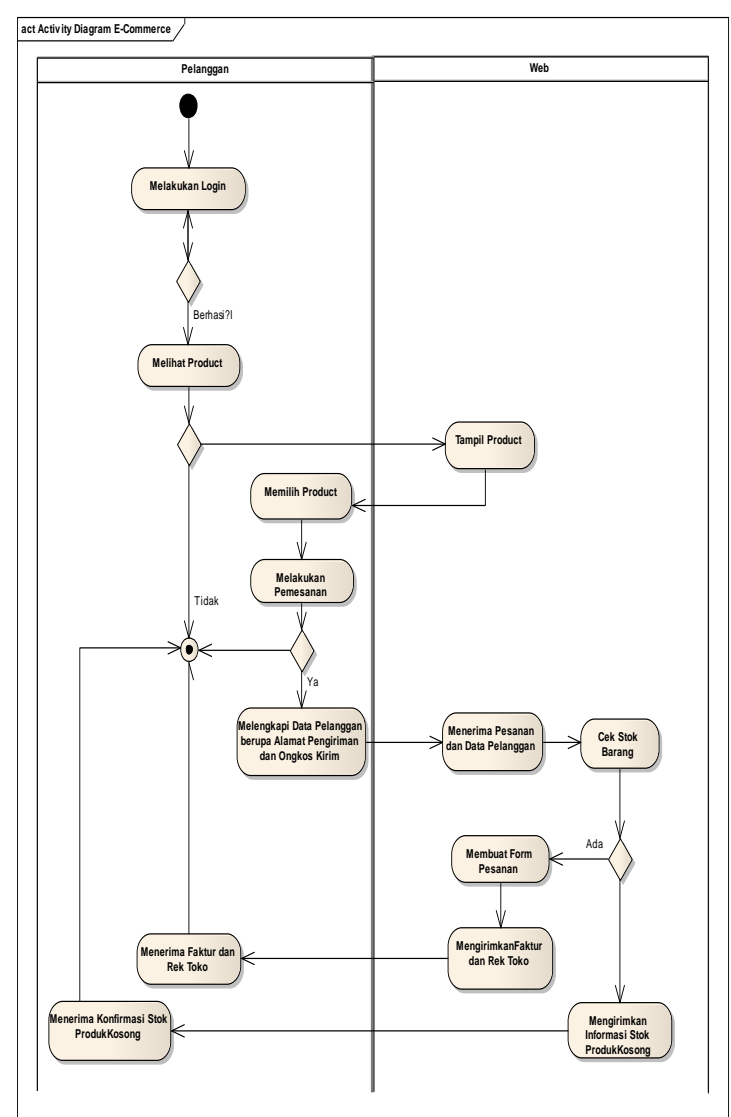

Gambar 9. Activity Diagram Pemesanan Produk

\section{Tampilan Web}

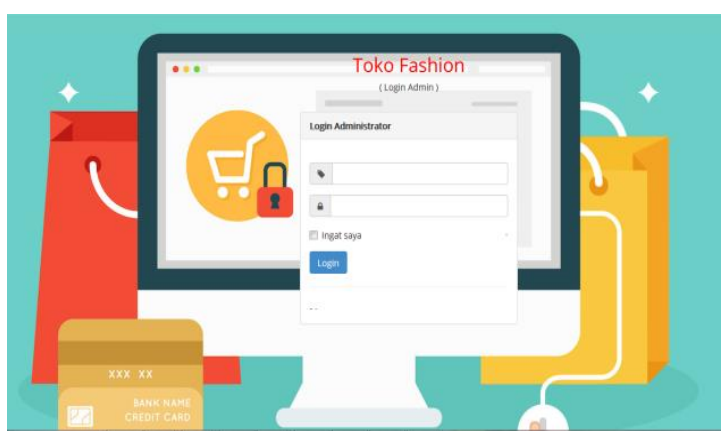

Gambar 10. Login Admin

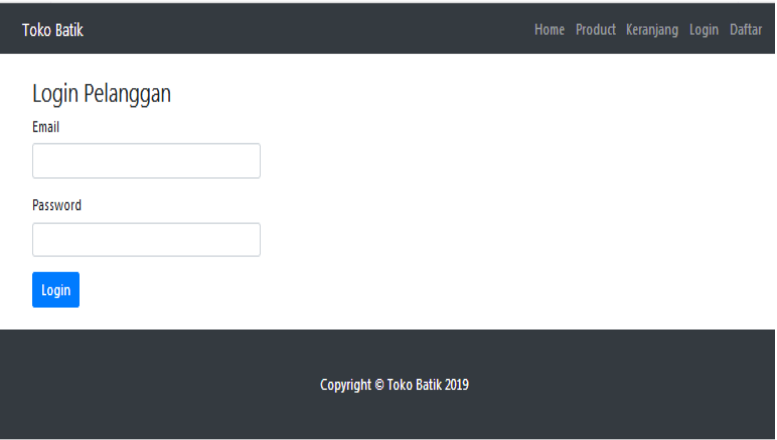

Gambar 11. Login Pelanggan

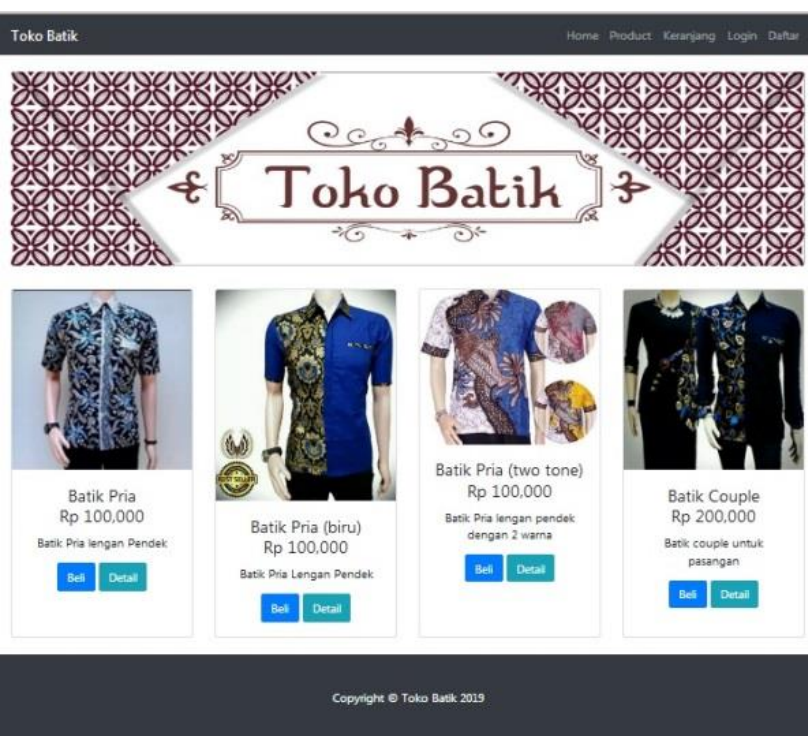

Gambar 12. Menu Utama

\section{KESIMPULAN}

Penjualan online menjadi solusi terbaik, sebagai media pemasaran dan media promosi batik pekalongan oleh siapa pun, dimana pun dan kapan pun, website e-commerce memudahkan pemilik toko untuk memberikan pelayanan kepada konsumen secara maksimal dan dapat dilakukan selama 24 jam. Keamanan dalam pengembangan website ecommerce menjadi permasalahan tersendiri sehingga untuk penelitian selanjutnya dapat dilakukan dengan metode-metode yang dapat memecahkan permasalahan tersebut.

\section{REFERENSI}

Arief, M. R. (2011). Pemrograman Web Dinamis Menggunakan Php dan MySql. Yogyakarta: Andi.

Brady, M., \& Loonam, J. (2010). Exploring the use of Entity-relationship diagramming as a Technique to Support Grounded Theory Inquiry. Bradford: Emerald Group.

Himawan, H., Saefullah, A., \& Santoso, S. (2018). Analisa dan Perancangan Sistem Informasi Penjualan Online (E-Commerce) pada CV Selaras Batik Menggunakan Analisis Deskriptif. Scientific Journal of Informatics, 1(1), 53-63. http://doi.org/10.15294/sji.v1i1.3641

Nugroho, A. (2010). Rekayasa Perangkat Lunak Berbasis Objek dengan Metode USDP. Yogyakarta: Andi.

Sadeli. (2013). Toko Baju Online Dengan PHP dan MySQL. Palembang: Maxikom.

Sukamto, R. ., \& Shalahudin, M. (2014). Rekayasa Perangkat Lunak Terstruktur dan Berorientasi Objek. Bandung: Informatika. 


\section{PROFIL PENULIS}

Nia Nuraeni, M.Kom. Tahun 2012 lulus dari Program Strata Satu (S1)Program Studi Sistem Informasi STMIK Nusa Mandiri Jakarta. Tahun 2015 Lulus dari Program Strata Dua (S2) Program Studi Ilmu Komputer STMIK Nusa Mandiri Jakarta.

Puji Astuti, M.Kom. Tahun 2012 lulus dari Program Strata Satu (S1) Program Studi Sistem Informasi STMIK Nusa Mandiri Jakarta. Tahun 2015 lulus dari Program Strata Dua (2) Program Studi Ilmu Komputer STMIK Nusa Mandiri Jakarta. 